\title{
Patient-to-patient transmission of hepatitis $C$ virus (HCV) during colonoscopy diagnosis
}

\author{
Fernando González-Candelas 1,3,4, Silvia Guiral², Rosa Carbó2, Ana Valero ${ }^{3,5}$, Hermelinda Vanaclocha², \\ Francisco González², Maria Alma Bracho 1,3,4*
}

\begin{abstract}
Background: No recognized risk factors can be identified in 10-40\% of hepatitis C virus (HCV)-infected patients suggesting that the modes of transmission involved could be underestimated or unidentified. Invasive diagnostic procedures, such as endoscopy, have been considered as a potential HCV transmission route; although the actual extent of transmission in endoscopy procedures remains controversial. Most reported HCV outbreaks related to nosocomial acquisition have been attributed to unsafe injection practices and use of multi-dose vials. Only a few cases of likely patient-to-patient HCV transmission via a contaminated colonoscope have been reported to date. Nosocomial HCV infection may have important medical and legal implications and, therefore, possible transmission routes should be investigated. In this study, a case of nosocomial transmission of HCV from a common source to two patients who underwent colonoscopy in an endoscopy unit is reported.

Results: A retrospective epidemiological search after detection of index cases revealed several potentially infective procedures: sample blood collection, use of a peripheral catheter, anesthesia and colonoscopy procedures. The epidemiological investigation showed breaches in colonoscope reprocessing and deficiencies in the recording of valuable tracing data. Direct sequences from the NS5B region were obtained to determine the extent of the outbreak and cloned sequences from the E1-E2 region were used to establish the relationships among intrapatient viral populations. Phylogenetic analyses of individual sequences from viral populations infecting the three patients involved in the outbreak confirmed the patient pointed out by the epidemiological search as the source of the outbreak. Furthermore, the sequential order in which the patients underwent colonoscopy correlates with viral genetic variability estimates.
\end{abstract}

Conclusions: Patient-to-patient transmission of HCV could be demonstrated although the precise route of transmission remained unclear. Viral genetic variability is proposed as a useful tool for tracing HCV transmission, especially in recent transmissions.

\section{Background}

$\mathrm{HCV}$ is predominantly transmitted by the parenteral route in procedures such as unscreened blood transfusions, injections related to intravenous drug use (IDU), injections related to health-care procedures, invasive medical and surgical interventions and, to a lesser extent, other percutaneous exposures [1-3]. Perinatal or sexual transmissions are considered far less efficient than transmission through large or repeated parenteral exposure [1,4-6]. Current HCV prevalence worldwide is far from

\footnotetext{
* Correspondence: alma.bracho@uv.es

'Centre Superior d'Investigació en Salut Pública (CSISP), Àrea de Genòmica i

Salut, Conselleria de Sanitat, Generalitat Valenciana, València, Spain

Full list of author information is available at the end of the article
}

even $[4,5]$ and is expected to fluctuate according to both availability and adherence to prevention measures at health-care facilities and also to changes in IDU-related habits [5]. HCV prevalence, estimated to be about $3 \%$ in 1999 [7], is mainly due to past infected blood transfusions and past and present injected drug use. Due to the asymptomatic nature of most HCV infections, the epidemic remains largely unnoticed with most chronic cases having been infected years ago, and with relatively few cases of acute infections being reported [8].

Interestingly, risk factors accounting for infection remain unknown in $10-40 \%$ of the patients with acute or chronic hepatitis $C[6,9]$. In contrast to chronic hepatitis, cases of recent $\mathrm{HCV}$ infection could shed greater

\section{() Biomed Central}


light on mechanisms of HCV transmission because the source of infection can be traced more accurately [8]. $\mathrm{HCV}$ infection associated with medical procedures, which are still unrecognised or underestimated, is an issue of great concern $[8,10]$. A nosocomial HCV mode of transmission that remains controversial is diagnostic or therapeutic digestive endoscopy (gastroscopy and colonoscopy). These infection routes are not even mentioned in recent reviews specifically dealing with the epidemiology of $\mathrm{HCV}$ infection $[4,5]$, although they receive varying attention in others $[3,6]$.

The first patient-to-patient hepatitis $\mathrm{C}$ transmission through colonoscopy was reported by Bronowicki et al. in 1997 [11]. Since then, a full consensus has been reached about the relationship between strict adherence to standard safety measures and null risk of transmission via endoscopy or endoscopy-related procedures $[12,13]$. However, further doubts have been casted on the true extent of $\mathrm{HCV}$ transmission via these procedures, ranging from rarely reported [13] to underestimated [14]. Two case-control studies carried out in France reported significant association between $\mathrm{HCV}$ infection and endoscopy procedures $[15,16]$. These studies showed that no significant decrease in this endoscopy-associated risk was found between 1980 and 1999 [15], and that HCV was still transmitted in France through specific invasive procedures including digestive endoscopy, at least, until 2002 [16].

A problem associated with identifying the source of nosocomial HCV infection is that retrospective transmission studies often fail to identify the exact procedure causing infection $[10,14]$. Hence, only well-documented case reports contribute to providing evidence for this particular HCV transmission in healthcare units. In two recent studies of patient-to-patient $\mathrm{HCV}$ transmission in endoscopy units $[17,18]$, unsafe injection practices performed on medication multi-dose vials or single-dose vials used in multiple patients, accounted for the respective nosocomial outbreaks.

In the present report, the transmission of $\mathrm{HCV}$ in an outbreak involving three patients attending an endoscopy unit is studied. Two of these patients tested HCV positive shortly after undergoing colonoscopy. An epidemiological investigation was combined with the use of molecular biology techniques and genetic and phylogenetic analyses to identify the origin of the outbreak and the transmission route. This reveals the importance of viral genetic variability estimates as a valuable complement to epidemiological search.

\section{Results}

\section{Epidemiological Investigation}

On February 2006, two regular blood donors were independently diagnosed with acute $\mathrm{HCV}$ infection. Both individuals had undergone colonoscopy procedures at the same endoscopy unit on December $19^{\text {th }}, 2005$. These two patients (C2 and C3) had tested negative for $\mathrm{HCV}$ prior to colonoscopy. Thus, the time of putative transmission was considered to be comprised between the last HCV negative test of these patients and the dates of their onset of symptoms (Figure 1 and Table 1). The initial wide case-finding investigation focused on recorded HCV status of patients attending the colonoscopy unit from July 2005 to February 2006 and did not

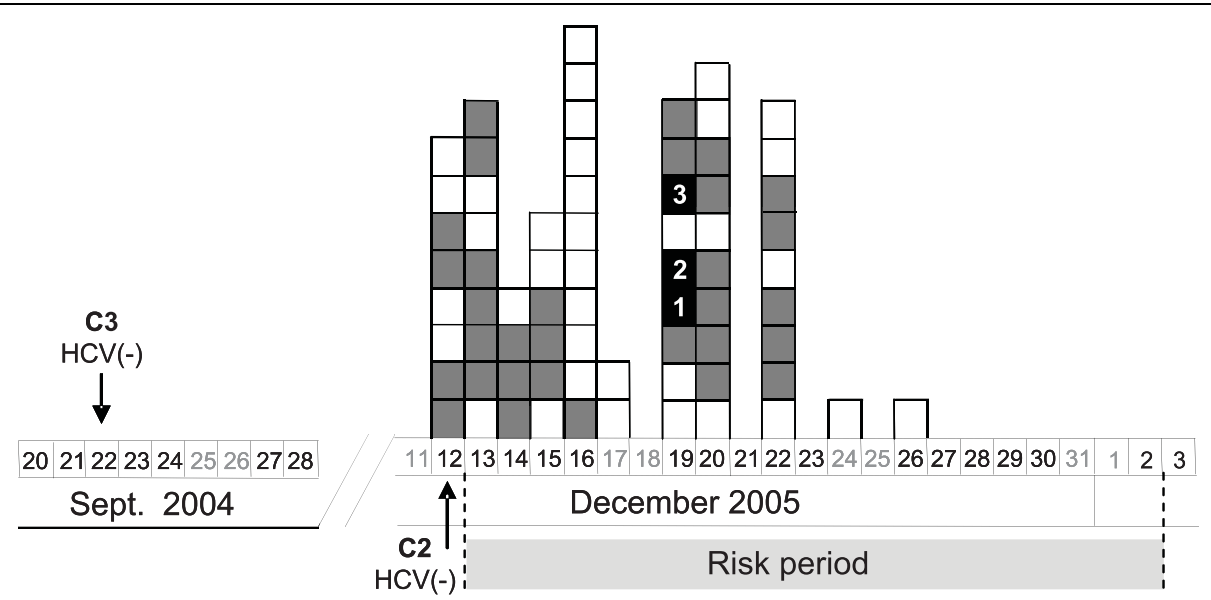

Figure 1 Chronological order of endoscopy procedures by date. Chronological scheme of the group of patients analyzed. Boxes represent endoscopy procedures performed to patients who attended the diagnostic unit. Patient order is deduced from the bottom to the top of the column. White boxes correspond to gastroscopies; grey boxes to colonoscopies and black boxes to colonoscopies and outbreak cases. Arrows indicate the date of the last negative HCV-RNA test for patients C2 and C3. It can be deduced from the columns that the order in which endoscopies performed on $19^{\text {th }}$ December 2005 was: gastroscopy, gastroscopy, colonoscopy, patient C1 colonoscopy, patient C2 colonoscopy, gastroscopy, patient C3 colonoscopy, colonoscopy and colonoscopy. 
Table 1 Epidemiological data.

\begin{tabular}{|c|c|c|c|}
\hline Patient & C1 & $\mathrm{C2}$ & $\mathrm{C} 3$ \\
\hline Type of case & Prevalent & Incident & Incident \\
\hline First symptoms & Asymptomatic & $17 / 01 / 2006$ & 26/01/2006 \\
\hline HCV-negative test & No & $12 / 12 / 2005$ & 22/09/2004 \\
\hline HCV subtype & $1 b$ & $1 \mathrm{~b}$ & $1 b$ \\
\hline \multicolumn{4}{|l|}{ Previous risk factors } \\
\hline Contact with HCV (3 years) & No & $\mathrm{Yes}^{a}$ & No \\
\hline Invasive diagnose or treatment & Colonoscopy (2001) & Acupuncture (Feb.-July 2005) & No \\
\hline Surgery & $\begin{array}{c}\text { Caesareas } \\
\text { (1984 and 1987) }\end{array}$ & No & No \\
\hline \multicolumn{4}{|l|}{ Risk factors at the endoscopy unit } \\
\hline Admission day & $19 / 12 / 2005$ & $19 / 12 / 2005$ & 19/12/2005 \\
\hline Blood collection and intravenous line insertion: order & $1^{\text {st }}$ & $3^{\text {rd }}$ & $2^{\text {nd }}$ \\
\hline Sedation and colonoscopy: order & $1^{\text {st }}$ & $2^{\text {nd }}$ & $3^{\text {rd }}$ \\
\hline Biopsy & No & No & Yes $^{b}$ \\
\hline
\end{tabular}

reveal any suspect of nosocomial infection. Next, a more limited and detailed case-finding search was carried out among all attendants to the same endoscopy unit between December $12^{\text {th }}, 2005$ and December $26^{\text {th }}, 2005$. Apart from the two index cases, 39 patients matched temporal criteria, but three were excluded due to exitus. The active search for $\mathrm{HCV}$-infected cases among these 36 eventually exposed patients (30 of which had gone through colonoscopy and the remaining 6 through gastroscopy) revealed two asymptomatic $\mathrm{HCV}$-positive individuals ( $\mathrm{C} 1$ and $\mathrm{C} 4)$. The epidemiological questionnaire indicated that patient $\mathrm{C} 1$, but not patient $\mathrm{C} 4$, had also undergone a colonoscopy on the same day as patients $\mathrm{C} 2$ and $\mathrm{C} 3$.

HCV subtypes for patients $C 1, C 2$ and $C 3$ were $1 b$, while that of $\mathrm{C} 4$ was subtype $2 \mathrm{c}$. This patient was considered to be unrelated to the outbreak and was removed from further analyses. Relevant features and nosocomial risk factors of patients $\mathrm{C} 1, \mathrm{C} 2$ and $\mathrm{C} 3$ are shown in Table 1 . On December, $19^{\text {th }}, 6$ other patients had undergone endoscopy diagnosis (3 gastroscopies and 3 colonoscopies) (Figure1). Data extracted from epidemiological questionnaires (Table 1) strongly indicated that patient $\mathrm{C} 1$ was the likely source of infection of the two incident cases. One additional patient underwent gastroscopy between colonoscopies practiced on patients $\mathrm{C} 1$ and $\mathrm{C} 2$ (Figure 1) but tested negative for HCV.

The epidemiological investigation focused on determining the transmission route. The procedures that could have led to patient-to-patient infection were examined: (a) blood collection and peripheral intravenous line placement and (b) sedation in the endoscopy room, later followed by colonoscopy. In the former, usual practices and decision-making about materials largely depend on the nurse in charge. Patient-nurse assignment was not recorded although it could be traced after interviews, and written protocols were not available. In spite of this, interviews to nurses did not reveal any failure in disinfection standards applied to bloodrelated practices.

The same anaesthesiologist, endoscopist, two nurses and auxiliary nurse performed anesthesia, colonoscopy procedure and nurse assistance, respectively, on all patients that underwent endoscopies on December $19^{\text {th }}$, including patients $\mathrm{C} 1, \mathrm{C} 2$ and $\mathrm{C} 3$. Written records documented that these three patients received parentally midazolam, propofol and anfentanil for anesthetic purposes. The patient that underwent gastroscopy between colonoscopies practiced on patients $\mathrm{C} 1$ and $\mathrm{C} 2$ received propofol and lidocaine. It could not be checked whether medication vials were multi- or mono-dose and whether they were used on more than a patient. Written protocols for sedation were not available. Interviews of medical personnel related to sedation procedures did not reveal any failure in preventive measures of infection.

The endoscopy unit had two colonoscopes, for which traceability failures were detected in patient assignment and disinfection records. A registered processing label recovered from the supply unit of endoscopes along with data from questionnaires established that patient order in sedation and colonoscopy was C1, C2 and C3 (Table 1). Biopsy specimens were obtained only from patient $\mathrm{C} 3$ by means of sterilized forceps provided by the central sterilization unit. Although it was not possible to verify whether the same colonoscope had been used with patients $\mathrm{C} 1, \mathrm{C} 2$ and $\mathrm{C} 3$, examination of the endoscope disinfection routines could not rule out this possibility. General standard guidelines for 
decontamination included manual cleaning of equipment followed by automatic disinfection. According to the available written protocol, obstruction of colonoscope channels with gastrointestinal debris could not be ruled out completely. In this procedure, colonoscope channels were flushed and rinsed with water and externally washed. After removing the valves, colonoscopes were immersed in enzymatic detergent and brushed manually. Individual clearance of all colonoscopy channels was not checked. Next, channels were rinsed with cleansing solution and introduced into the automaticwasher disinfector. As for the automatic step, correct disinfection of colonoscopes could not be checked due to a failure of the printer connected to the disinfection device. In addition, technical staff members in charge of colonoscope disinfection had not received specific training.

\section{Phylogenetic analyses and viral variability}

Partial NS5B sequences obtained from patients C1 and $\mathrm{C} 2$ were identical and only differed in three of 337 positions from the sequence corresponding to patient C3. As a result, the phylogenetic tree of the NS5B region (Figure 2) showed that patients C1, C2 and C3 clearly clustered in a monophyletic group among sequences belonging to $\mathrm{HCV}$ subtype 1b (bootstrap support 77\%). The analysis of the NS5B region clearly defined the extent of the outbreak. As expected in a well-defined outbreak, the genetic distances between sequences belonging to patients $\mathrm{C} 1, \mathrm{C} 2$ and $\mathrm{C} 3$ were substantially shorter than those between them and local reference sequences from epidemiologically unrelated patients (Figure 2). In addition, another well-supported cluster also appeared among the reference sequences probably indicating local epidemiological links between three isolates in the past. Monophyletic clustering of sequences in the phylogenetic tree of the conserved NS5B region enabled us to define the patients involved in the outbreak. In order to further characterize the respective $\mathrm{HCV}$ viral populations, the highly variable E1-E2 region of $\mathrm{HCV}$ was analysed.

Thus, sequences from 74 cloned fragments of the E1E2 region, encompassing the hypervariable region (HVR), were obtained from patients C1, C2 and C3 (26, 28 and 20 sequences respectively). In order to avoid redundancy, only unique sequences within each patient were used in phylogenetic analysis. Therefore, a total of 38 sequences $(21,15$ and 2 unique sequences from patients $\mathrm{C} 1, \mathrm{C} 2$ and $\mathrm{C} 3$, respectively) were included in the phylogenetic analysis.

These E1-E2 cloned sequences were analysed along with 35 local reference sequences from epidemiologically unrelated patients. The resulting phylogenetic tree, in which only different sequences within patient were

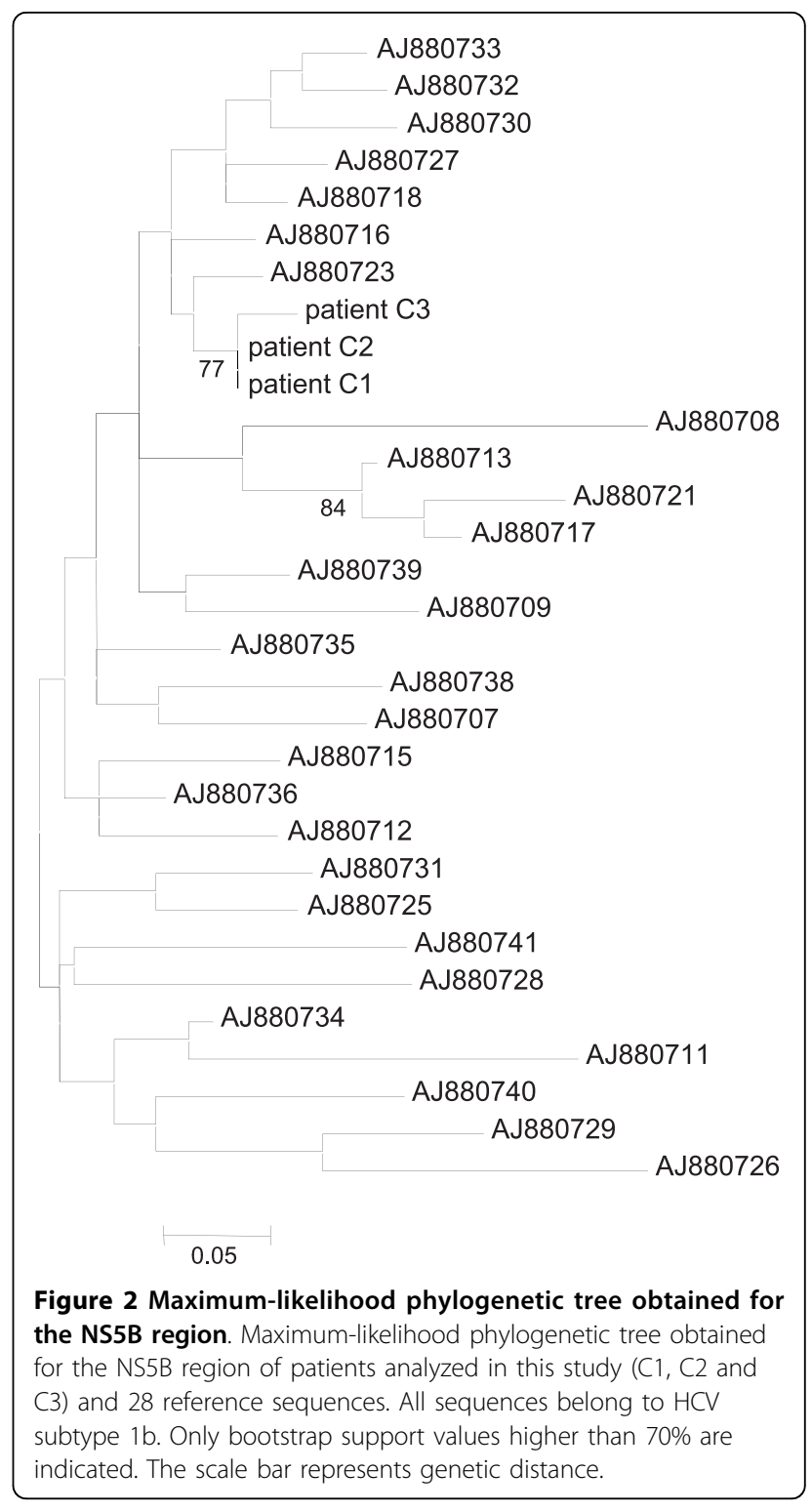

included, is shown in Figure 3. Sequences of clones from patients involved in the outbreak gave rise to a well-supported monophyletic group (bootstrap support $80 \%)$. Most of the 21 different cloned sequences obtained from patient $\mathrm{C} 1$ were unique and showed relatively short distances from each other. However, two divergent sequences were also present among the isolated cloned sequences. Patient C2 provided 15 different cloned sequences, some of which were repeatedly sampled between 2 and 8 times. All these sequences mixed with those from the main cluster of patient $\mathrm{C} 1$ sequences in the phylogenetic tree (Figure 3). Moreover, two sequences from patient $\mathrm{C} 1$ were also detected in patient C2 (one was sampled three times and the other eight times). Finally, patient C3 presented two unique 


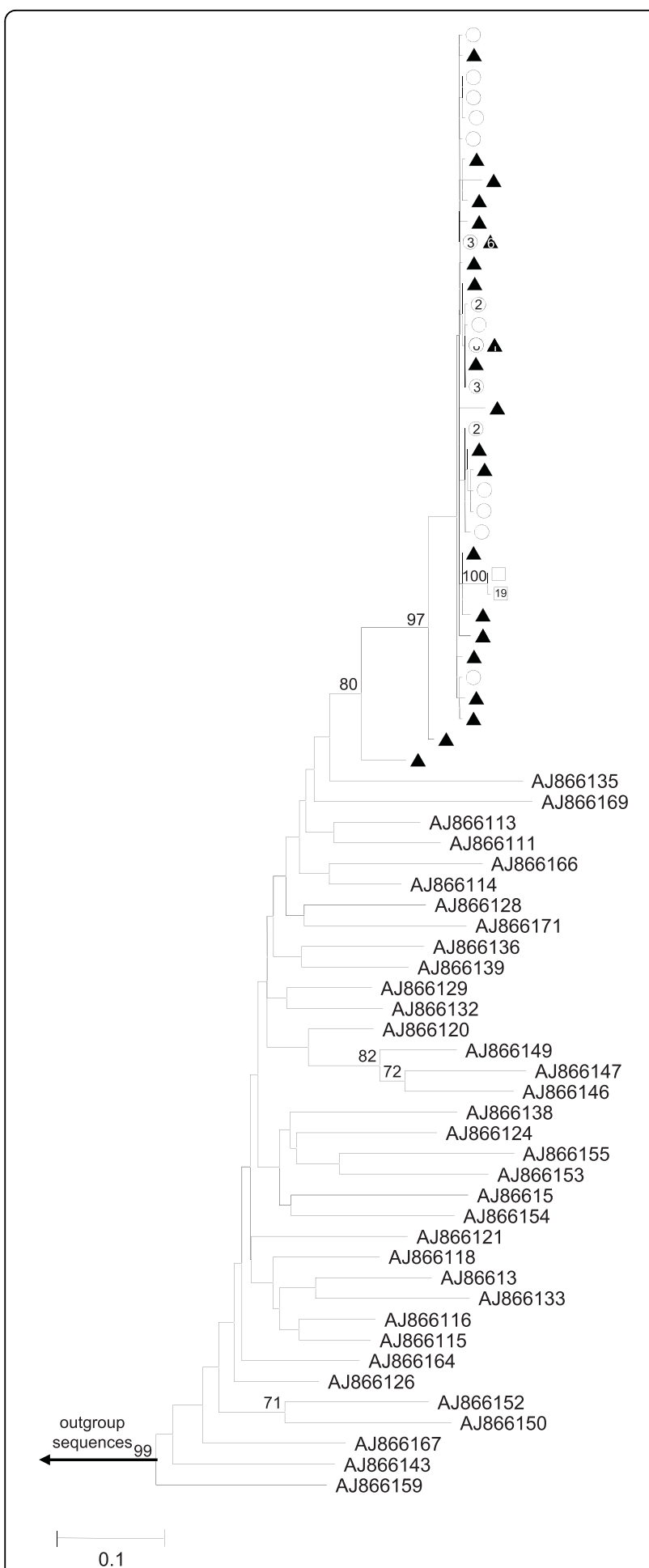

Figure 3 Maximum-likelihood phylogenetic tree obtained for the E1-E2 region. Maximum-likelihood phylogenetic tree obtained for the E1-E2 region of cloned sequences from patient C1 (black triangles), patient C2 (white circles), patient C3 (white squares) and 35 reference sequences. Numbers inside shapes indicate number of identical sequences sampled. All sequences belong to HCV subtype 1b. Only bootstrap support values higher than $70 \%$ are indicated.

The scale bar represents genetic distance. cloned sequences which grouped in a differentiated cluster (bootstrap support 100\%) also located among sequences of the main cluster of patient $\mathrm{C} 1$ sequences, with one sequence sampled 19 times and the other only once (Figure 3). In congruence with the phylogenetic tree of the NS5B region, genetic distances between E1-E2 sequences from patients C1, C2 and C3 were much shorter than those between these and the reference sequences.

The outbreak pattern in phylogenetic trees, i. e. monophyletic cluster of outbreak-related sequences, is obvious in both NS5B and E1-E2 regions. However, due to the larger number of mutations accumulated in the more variable E1-E2 region, genetic distances in this portion of the genome can provide additional information on how viral populations have emerged in patients involved in the outbreak. Two additional well-supported clusters appeared among the reference sequences for the E1-E2 region (Figure 3), probably indicating local epidemiological links involving two and three isolates, respectively.

Intrapatient genetic variability for the E1-E2 region estimates (Table 2) showed the highest variability for patient $\mathrm{C} 1$ viral population in all parameters (haplotype diversity, number of polymorphic sites, total number of mutations, nucleotide diversity and average number of nucleotide differences between pairs of sequences) followed by lower values for patient $\mathrm{C} 2$ and the lowest genetic variability corresponding to patient C3. For instance, nucleotide diversity $(\pi)$ of patient $\mathrm{C} 1$ viral population was one and two orders of magnitude larger than those of patients $\mathrm{C} 2$ and $\mathrm{C} 3$, respectively. Therefore, these estimates showed a pronounced decrease in genetic variability from patient $\mathrm{C} 1$ to patient $\mathrm{C} 3$ $(\mathrm{C} 1>\mathrm{C} 2>\mathrm{C} 3)$. In a reconstructed scenario, first, a viral inoculum from patient $\mathrm{C} 1$ was in contact with patient $\mathrm{C} 2$ and later with patient $\mathrm{C} 3$. An unidentified factor could have reduced the remaining viral population after infecting patient $\mathrm{C} 2$, but left enough viral load to cause infection in patient $\mathrm{C} 3$.

Table 2 Summary of intrapatient genetic variability for the E1-E2 region of $\mathrm{HCV}-1 \mathrm{~b}$ analyzed in this study

\begin{tabular}{llllllll}
\hline Patient & $\mathbf{n}^{\mathbf{a}}$ & $\mathbf{h}^{\mathbf{b}}$ & $\mathbf{H} \mathbf{d}^{\mathbf{c}, \mathbf{h}}$ & $\mathbf{S}^{\mathbf{d}}$ & $\boldsymbol{\eta}^{\mathbf{e}}$ & $\boldsymbol{\pi}^{\mathbf{f , h}}$ & $\kappa^{\mathbf{g , h}}$ \\
\hline $\mathbf{C 1}$ & 26 & 21 & $0.954(0.035)$ & 78 & 79 & $0.01698(0.00567)$ & $9.034(4.300)$ \\
$\mathbf{C 2}$ & 28 & 15 & $0.905(0.042)$ & 17 & 17 & $0.00622(0.00083)$ & $3.310(1.753)$ \\
$\mathbf{C 3}$ & 20 & 2 & $0.100(0.088)$ & 1 & 1 & $0.00019(0.00017)$ & $0.100(0.179)$ \\
\hline
\end{tabular}

${ }^{a} n$, number of clone sequences.

${ }^{b} h$, number of different haplotypes.

${ }^{\mathrm{c}} \mathrm{Hd}$, haplotype diversity.

${ }^{\mathrm{d}} \mathrm{S}$, number of polymorphic sites.

$\mathrm{e} \eta$, total number of mutations.

${ }^{f} \pi$, nucleotide diversity.

${ }^{g} \kappa$, average number of nucleotide differences between pairs of sequences.

${ }^{\mathrm{h}} \mathrm{Standard}$ deviations are reported in parentheses. 


\section{Discussion}

In the present study, an approach combining epidemiological investigation with a molecular strategy involving both phylogenetic and genetic variability characterization was implemented to ascertain the most likely explanation for two iatrogenic infections. This report of an outbreak of two acute HCV among three outpatients, attending an endoscopy unit on the same day, provides a case study of nosocomial HCV transmission. Phylogenetic analyses using NS5B and E1-E2 viral regions clearly defined the extent of the outbreak.

The fact that an HCV negative patient had undergone gastroscopy between colonoscopies practiced between patient $\mathrm{C} 1$ and $\mathrm{C} 2$ along with the fact that all three $\mathrm{HCV}$-infected patients underwent colonoscopy, led the investigation to consider colonoscopy, and not gastroscopy, as a risk factor for the outbreak. Hence, common procedures practiced before gastroscopies and colonoscopies, although fully examined, were considered not to have played a relevant role in the patient-to-patient transmission.

Therefore, nosocomial infection occurred during colonoscopy procedure, but the recovered epidemiological data could not clearly settle whether the transmission resulted from eventual contamination of medication vials or incomplete disinfection of colonoscopes. The lack of information related to vials used in sedation and the lack of traceability in the use of colonoscopes have limited our ability to detail how transmission occurred. A similar dilemma could not be resolved in the pioneering case report of $\mathrm{HCV}$ transmission during colonoscopy [11] in which the authors were unable to completely rule out the possibility that HCV transmission occurred during the anaesthesia procedure previous to the colonoscopy. Similar uncertainty was also expressed in other case reports studying HCV transmission during colonoscopy diagnosis $[19,20]$. However two recent reports have successfully solved that unsafe injection practices performed with medication vials accounted for nosocomial infections [17,18]. In fact, several studies have shown that unsafe injection practices related to anesthesia or intravenous medication are more often involved in $\mathrm{HCV}$ and HBV transmission than the equipment used in medical procedures with the patients $[10,18]$. In this respect, reuse of single or multiple-dose medication vials on multiple patients appears as the most common risk factor associated to minor invasive procedures such as colonoscopies $[17,18]$. The strict adherence to disinfection standards on diagnosis instruments and the application of safe injection practices fully described elsewhere $[10,17,18,20]$ would prevent such nosocomial patient-topatient infections definitively.
It has often been observed that, in the absence of treatment, a viral population from chronically infected patients tends to gradually accumulate genetically diverse viral variants over time $[21,22]$. On the other hand, a viral population from recently infected patients tends to display lower genetic diversity than the viral population from the source [23]. Although viral load of inoculums, transmission pathway or host factors, such as susceptibility to infection or a particular immune system response, may play a role in the emergence of viral populations, the pattern of decreasing variability of viral populations from source patient to newly infected patient should be met. Virus sequences isolated from patient $\mathrm{C} 1$ displayed the highest intrapatient variability in the E1-E2 region, which is a feature of the oldest infection. Intrapatient variability was lower in patient $\mathrm{C} 2$, while in patient $\mathrm{C} 3$ it was minimal, thus matching the order in which they underwent sedation and colonoscopy. A similar relationship has already been observed in other nosocomial transmission case of $\mathrm{HCV}$ (Bracho, unpublished results). As the exact route of transmission could not be ascertained, two alternative hypothesis of progressive viral load reduction of the infective inoculums can be formulated. If infection occurred via contaminated medication, initial infective virions from patient $\mathrm{C} 1$ could have undergone progressive deterioration in an inappropriate media so that patient $\mathrm{C} 3$ received a much more limited representation of the diversity present in the source viral population than the previously infected patient (i.e. patient $\mathrm{C} 2$ ). If infection occurred via colonoscope, the colonoscope contaminated with virions from patient $\mathrm{C} 1$ could have undergone two incomplete disinfection cycles. This procedure, performed after colonoscopy practiced on patient $\mathrm{C} 1$ and later on patient $\mathrm{C} 2$, could have reduced the viral population in the colonoscope progressively. Therefore, independently of the true route of transmission, a reduction in viral diversity is predicted under both scenarios.

Thus, these results, in congruence with but independently of the epidemiological investigation, support that patient $\mathrm{C} 1$ was the source of this outbreak and that it is highly likely that infection to patients $\mathrm{C} 2$ and $\mathrm{C} 3$ occurred during the colonoscopy procedure. A typical pattern in phylogenetic trees, the monophyletic clustering of outbreak-related sequences with high bootstrap support, is often recognized when using consensus sequences of cases and controls from either conserved (core, NS5B) or variable regions (E1-E2) of the HCV genome. These sequences are obtained through direct sequencing of PCR products and their use is limited to determining which patients are involved in the putative outbreak [12,24-27]. Mutations accumulate in viral 
populations mainly as a function of time and evolutionary rate, which is substantially larger for hypervariable regions $[28,29]$. Hence, genetic distances are larger in variable regions than in more conserved ones and, when calculated for intrapatient viral populations, provide a useful tool for relating genetic variability to the time elapsed since infection. This is especially the case in the characterization of recent transmissions [23]. As a consequence, accurate determination of the infection source, especially in rapidly detected outbreaks, is best tackled by the phylogenetic analysis of individual (cloned or end-point diluted) sequences of a fast evolving region $[17,18,30]$ and complemented with genetic variability estimation of the intrapatient viral populations [23]. The combination of these two procedures will improve the resolution of molecular studies of outbreaks over that of analyses based only on consensus sequences.

\section{Conclusions}

Based on examination of data collected by an epidemiological investigation, and genetic and phylogenetic results, we conclude that patient-to-patient transmission probably occurred sequentially during colonoscope procedures. The exact route of transmission, putatively through intravenous medications or colonoscope, could not be determined. The comparison of intrapatient viral genetic variability estimates is proposed as a powerful tool for tracing HCV transmission. As prevention of nosocomial transmissions should be a prime concern, our study contributes to reinforce the importance of implementing good practices in invasive diagnosis.

\section{Methods \\ Epidemiological investigation}

The newly HCV positivity of the two index patients after undergoing colonoscopy in a private endoscopy unit on $19^{\text {th }}$ December, 2005 lead to a retrospective survey to study a possible nosocomial transmission. First, a wide case-finding investigation included reviewing $\mathrm{HCV}$ positive and negative records from all local Microbiology Units between January 2004 and February 2006 (eight hospitals, including the one under study) of patients that had undergone endoscopy procedures between July 2005 and February 2006 at the endoscopy unit. A second, more limited and detailed search involved all patients who had attended the endoscopy unit one week before and after the date considered. This investigation covered review of clinical records for 39 patients matching temporal criteria. All these patients, except three due to exitus, were actively contacted, informed about the possibility of exposure to $\mathrm{HCV}$ and tested for anti$\mathrm{HCV}$. The 36 patients completed a detailed epidemiological questionnaire on risk factors for $\mathrm{HCV}$ infection including history of transfusion, intravenous drug use, piercing, tattooing, acupuncture and suspicion of nosocomial transmission. In order to rule out delayed seroconversion, the six patients that had undergone colonoscopy or gastroscopy on $19^{\text {th }}$ December, 2005 and tested negative for HCV in February 2006, were retested 6 months later. All of them were found to be anti-HCV negative at that time. Healthcare staff involved in performing endoscopy (one gastroenterologist, one anesthesiologist, seven nurses and one nurse's aide) had negative HCV status in February 2006.

An epidemiological investigation to determine risk procedures leading to $\mathrm{HCV}$ transmission during endoscopies was also carried out. This included a description of the facilities, review of clinical practices and procedures performed between admission and discharge, description of staff member qualifications and assessment of disinfection procedures and devices (i.e. observation of endoscopic procedures and endoscopic reprocessing, and observation of procedures regarding intravenous line insertion for anaesthetic purposes). All healthcare workers were interviewed about infectioncontrol practices.

\section{Patients and specimens}

Serum samples were obtained from four $\mathrm{HCV}$-infected patients $(\mathrm{C} 1, \mathrm{C} 2, \mathrm{C} 3$ and $\mathrm{C} 4)$ referred to the endoscopy unit. Samples were taken on February 2006 and stored frozen at $-70^{\circ} \mathrm{C}$ until processed. Viral load of specimens was not measured.

\section{RNA extraction and RT-PCR of NS5B and E1-E2 regions}

Viral RNA was obtained from $200 \mu \mathrm{l}$ of serum from each sample using a High Pure Viral RNA Kit (Roche Diagnostics GmbH, Mannheim, Germany). Reverse transcriptions (RT) and PCRs were performed as described in Bracho et al. (2005) [23]. Amplified fragments were 337 and 532-nucleotide-long for NS5B and E1-E2 regions, respectively. Oligonucleotides used for amplification and direct sequencing of the NS5B region were 5'-TATGATACYCGCTGYTTYGACTC-3' (sense), 5'GTACCTRGTCATAGCCTCCGTGAA-3' (antisense), and for the amplification of the E1-E2 region, 5'-CGCATGGCYTGGGAYATGAT-3' (sense), 5'GGGGTGAARCARTAYACYGG-3' (antisense), and hemi-nested 5'-GGGATATGATRATGAAYTGGTC-3' (sense). A single amplified product for each region was observed after electrophoresis on a $1.4 \%$ agarose gel stained with ethidium bromide. Amplified products of the NS5B and E1-E2 regions were purified with High Pure PCR Product Purification Kit (Roche Diagnostics GmbH, Mannheim, Germany). The NS5B gene sequences were obtained directly with the ABI PRISM BigDye $^{\circ}$ Terminator v3.1 Cycle Sequencing Kit in an ABI 3730 (Applied Biosystems Foster City, CA) 
automated sequencer and amplification oligonucleotides as described in Bracho et al. (2005).

\section{Cloning and sequencing of the E1-E2 region}

Amplified fragments of the E1-E2 region, encompassing HVR1, HVR2 and HVR3 [22], were directly cloned in EcoRV-digested pBluescript II SK (+) phagemid (Stratagene, La Jolla, CA). Plasmid DNA was purified with a High Pure Plasmid Isolation kit (Roche). Recombinant plasmids were sequenced with KS and SK oligonucleotides (Stratagene) as described above.

\section{Phylogenetic and genetic analyses}

Partial NS5B sequences were genotyped using HCV BLAST search at Los Alamos HCV Sequence Database [31]. NS5B sequences from patients C1, C2, and C3 were analyzed along with a panel of 28 additional local sequences from epidemiologically unrelated isolates [23], including NS5B reference sequences for HCV subtype 1b. Accession numbers for the NS5B reference sequences (EMBL) are shown in Figure 1. Cloned sequences of the E1-E2 region, corresponding to the three patients infected with HCV subtype $1 \mathrm{~b}$, were analyzed along with 35 reference sequences of HCV subtype $1 \mathrm{~b}$. These E1-E2 reference sequences were also obtained from patients included in the above study [23]. The accession numbers for E1-E2 region reference sequences are shown in Figure 2. Prior to phylogenetic analysis of the E1-E2 region, unique cloned sequences within patient were selected using DAMBE software [32]. For both HCV genome regions, multiple sequence alignments were obtained using ClustalX 2.0.10 [33]. Phylogenetic trees were constructed by maximum likelihood with PhyML v3.0 [34] using the nucleotide substitution model that best fitted the data according to corrected Akaike Information Criterion (AICc) implemented in jModeltest 1.0.1 [35]. The evolutionary model that best explained the data in the NS5B region corresponded to TIM2 model distance [35], with a gamma distribution accounting for heterogeneity in evolutionary rates among sites (shape parameter $=1.034$ ) and a proportion of invariable sites $(\mathrm{I}=0.630)$. The evolutionary model that best explained the data for the E1-E2 region corresponded to Tamura-Nei [36], with a gamma distribution accounting for the heterogeneity in evolutionary rates among sites (shape parameter $=0.737$ ) and a proportion of invariable sites $(\mathrm{I}=0.273)$. In addition, a parallel analysis was carried out with E1-E2 cloned sequences from local reference patients instead of the corresponding consensus sequences, but the maximum likelihood tree yielded similar results (data not shown). Robustness of the clades derived in the phylogenetic trees was assessed by bootstrap analysis using 1000 pseudo-replicates as implemented in PhyML. Genetic variability estimates for the complete set of E1-E2 cloned sequences derived from patients $\mathrm{C} 1, \mathrm{C} 2$ and $\mathrm{C} 3$ were obtained with DnaSP v5 [37].

\section{Nucleotide sequence accession numbers}

The HCV sequences obtained in this study have been deposited in GenBank under accession numbers [EMBL: FM881903 to EMBL:FM881906] for NS5B region sequences and [EMBL:FM955149 to EMBL:FM955222] for clones of the E1-E2 region.

\section{Acknowledgements}

This work has been supported by Conselleria de Sanitat, also by ISCIII-FIS project CP07/00078 (MAB) from Ministerio de Sanidad y Consumo and project BFU2008-03000 (FG-C, MAB) from Ministerio de Ciencia e Innovación.

\section{Author details}

${ }^{1}$ Centre Superior d'Investigació en Salut Pública (CSISP), Àrea de Genòmica i Salut, Conselleria de Sanitat, Generalitat Valenciana, València, Spain. ${ }^{2}$ Direcció General de Salut Pública (DGSP), Àrea d'Epidemiologia, Conselleria de Sanitat, Generalitat Valenciana, València, Spain. Institut "Cavanilles" de Biodiversitat i Biologia Evolutiva (ICBiBE), Universitat de València, València, Spain. ${ }^{4}$ Centro de Investigación Biomédica en Red de Epidemiología y Salud Pública (CIBERESP), Ministerio de Ciencia e Innovación, Spain. ${ }^{5}$ Microbial Pathogenesis Unit, Centre for Infectious Diseases, University of Edinburgh, UK.

\section{Authors' contributions}

$S G, R C, H V$ and FG performed epidemiological investigation. AV made contribution to the sequence generation and submission, and drafted tables and figures. MAB and FG-C carried out the molecular genetic studies and wrote the manuscript. HV and FG-C coordinated the study. SG, RC, HV, FG, $M A B$ and $F G-C$ participated in the interpretation of data and critically revised the manuscript. All authors read and approved the final manuscript.

\section{Competing interests}

The authors declare that they have no competing interests.

Received: 23 July 2010 Accepted: 8 September 2010

Published: 8 September 2010

\section{References}

1. Rantala M, van de Laar MJ: Surveillance and epidemiology of hepatitis B and C in Europe - a review. Euro Surveill 2008, 13.

2. Rosen HR: Primer on hepatitis $\mathrm{C}$ for hospital epidemiologists. Infect Control Hosp Epidemiol 2000, 21:229-234.

3. Prati D: Transmission of hepatitis $C$ virus by blood transfusions and other medical procedures: a global review. J Hepatol 2006, 45:607-616.

4. Shepard CW, Finelli L, Alter MJ: Global epidemiology of hepatitis C virus infection. Lancet Infect Dis 2005, 5:558-567.

5. Sy $\mathrm{T}$, Jamal MM: Epidemiology of hepatitis $\mathrm{C}$ virus $(\mathrm{HCV})$ infection. Int J Med Sci 2006, 3:41-46.

6. Esteban JI, Sauleda S, Quer J: The changing epidemiology of hepatitis C virus infection in Europe. J Hepatol 2008, 48:148-162.

7. Global surveillance and control of hepatitis C. Report of a WHO Consultation organized in collaboration with the Viral Hepatitis Prevention Board, Antwerp, Belgium. J Viral Hepat 1999, 6:35-47.

8. Irving WL, Salmon D, Boucher C, Hoepelman IM: Acute hepatitis C virus infection. Euro Surveill 2008, 13.

9. Zeuzem S, Teuber G, Lee JH, Ruster B, Roth WK: Risk factors for the transmission of hepatitis C. J Hepatol 1996, 24:3-10.

10. Alter MJ: Healthcare should not be a vehicle for transmission of hepatitis C virus. J Hepatol 2008, 48:2-4.

11. Bronowicki JP, Venard V, Botte C, Monhoven N, Gastin I, Chone L, Hudziak H, Rihn B, Delanoe C, LeFaou A, et al: Patient-to-patient transmission of hepatitis C virus during colonoscopy. N Engl J Med 1997, 337:237-240. 
12. Bruguera M, Saiz JC, Franco S, Gimenez-Barcons M, Sanchez-Tapias JM, Fabregas S, Vega R, Camps N, Dominguez A, Salleras L: Outbreak of nosocomial hepatitis $C$ virus infection resolved by genetic analysis of HCV RNA. J Clin Microbiol 2002, 40:4363-4366.

13. Ciancio A, Manzini P, Castagno F, D'Antico S, Reynaudo P, Coucourde L, Ciccone G, Del Piano M, Ballare M, Peyre S, et al: Digestive endoscopy is not a major risk factor for transmitting hepatitis $\mathrm{C}$ virus. Ann Intern Med 2005, 142:903-909.

14. Martinez-Bauer E, Forns $X$, Armelles M, Planas R, Sola R, Vergara M, Fabregas $S$, Vega R, Salmeron J, Diago $M$, et al: Hospital admission is a relevant source of hepatitis C virus acquisition in Spain. J Hepatol 2008, 48:20-27.

15. Karmochkine M, Carrat F, Dos Santos O, Cacoub P, Raguin G: A casecontrol study of risk factors for hepatitis $\mathrm{C}$ infection in patients with unexplained routes of infection. J Viral Hepat 2006, 13:775-782.

16. Delarocque-Astagneau E, Pillonel J, De Valk H, Perra A, Laperche S, Desenclos JC: An incident case-control study of modes of hepatitis C virus transmission in France. Ann Epidemiol 2007, 17:755-762.

17. Fischer GE, Schaefer MK, Labus BJ, Sands L, Rowley P, Azzam IA, Armour P, Khudyakov YE, Lin Y, Xia G, et al: Hepatitis C Virus Infections from Unsafe Injection Practices at an Endoscopy Clinic in Las Vegas, Nevada, 20072008. Clin Infect Dis 2010, 51:267-273.

18. Gutelius B, Perz JF, Parker MM, Hallack R, Stricof R, Clement EJ, Lin Y, Xia GL, Punsalang A, Eramo A, et al: Multiple Clusters of Hepatitis Virus Infections Associated With Anesthesia for Outpatient Endoscopy Procedures. Gastroenterology 2010, 139:163-170

19. Le Pogam S, Gondeau A, Bacq Y: Nosocomial transmission of hepatitis C virus. Ann Intern Med 1999, 131:794.

20. Muscarella LF: Recommendations for preventing hepatitis $C$ virus infection: analysis of a Brooklyn endoscopy clinic's outbreak. Infect Control Hosp Epidemiol 2001, 22:669.

21. Cuevas JM, Torres-Puente M, Jimenez-Hernandez N, Bracho MA, GarciaRobles I, Wrobel B, Carnicer F, del Olmo J, Ortega E, Moya A, GonzalezCandelas F: Genetic variability of hepatitis $C$ virus before and after combined therapy of interferon plus ribavirin. PLoS One 2008, 3:e3058.

22. Torres-Puente M, Cuevas JM, Jimenez-Hernandez N, Bracho MA, GarciaRobles I, Wrobel B, Carnicer F, del Olmo J, Ortega E, Moya A, GonzalezCandelas F: Using evolutionary tools to refine the new hypervariable region 3 within the envelope 2 protein of hepatitis C virus. Infect Genet Evol 2008, 8:74-82.

23. Bracho MA, Gosalbes MJ, Blasco D, Moya A, Gonzalez-Candelas F: Molecular epidemiology of a hepatitis $C$ virus outbreak in a hemodialysis unit. J Clin Microbiol 2005, 43:2750-2755.

24. Forns X, Martinez-Bauer E, Feliu A, Garcia-Retortillo M, Martin M, Gay E, Navasa M, Sanchez-Tapias JM, Bruguera M, Rodes J: Nosocomial transmission of $\mathrm{HCV}$ in the liver unit of a tertiary care center. Hepatology 2005, 41:115-122.

25. Germain JM, Carbonne A, Thiers V, Gros H, Chastan S, Bouvet E, Astagneau P: Patient-to-patient transmission of hepatitis $C$ virus through the use of multidose vials during general anesthesia. Infect Control Hosp Epidemiol 2005, 26:789-792.

26. Panella H, Rius C, Cayla JA: Transmission of hepatitis $C$ virus during computed tomography scanning with contrast. Emerg Infect Dis 2008, 14:333-336.

27. Quer J, Esteban Jl, Sanchez JM, Otero T, Rius C, Coll M, Cubero M, Moreno G, Gonzalez A, Vaque J, et al: Nosocomial transmission of hepatitis $C$ virus during contrast-enhanced computed tomography scanning. Eur I Gastroenterol Hepatol 2008, 20:73-78.

28. Cuevas JM, Gonzalez M, Torres-Puente M, Jimenez-Hernandez N, Bracho MA, Garcia-Robles I, Gonzalez-Candelas F, Moya A: The role of positive selection in hepatitis C virus. Infect Genet Evol 2009, 9:860-866.

29. Gonzalez-Candelas F, Bracho MA, Moya A: Molecular epidemiology and forensic genetics: application to a hepatitis $C$ virus transmission event at a hemodialysis unit. J Infect Dis 2003, 187:352-358.

30. Ross RS, Viazov S, Khudyakov YE, Xia GL, Lin Y, Holzmann H, Sebesta C, Roggendorf $\mathrm{M}$, Janata $\mathrm{O}$ : Transmission of hepatitis $\mathrm{C}$ virus in an orthopedic hospital ward. J Med Virol 2009, 81:249-257.

31. Kuiken C, Yusim K, Boykin L, Richardson R: The Los Alamos hepatitis C sequence database. Bioinformatics 2005, 21:379-384.

32. Xia X, Xie Z: DAMBE: software package for data analysis in molecular biology and evolution. J Hered 2001, 92:371-373.
33. Larkin MA, Blackshields G, Brown NP, Chenna R, McGettigan PA, McWilliam H, Valentin F, Wallace IM, Wilm A, Lopez R, et al: Clustal W and Clustal X version 2.0. Bioinformatics 2007, 23:2947-2948.

34. Guindon S, Gascuel O: A simple, fast, and accurate algorithm to estimate large phylogenies by maximum likelihood. Syst Biol 2003, 52:696-704.

35. Posada D: jModelTest: phylogenetic model averaging. Mol Biol Evol 2008, 25:1253-1256.

36. Tamura K, Nei M: Estimation of the number of nucleotide substitutions in the control region of mitochondrial DNA in humans and chimpanzees. Mol Biol Evol 1993, 10:512-526.

37. Librado P, Rozas J: DnaSP v5: a software for comprehensive analysis of DNA polymorphism data. Bioinformatics 2009, 25:1451-1452.

doi:10.1186/1743-422X-7-217

Cite this article as: González-Candelas et al:: Patient-to-patient transmission of hepatitis C virus (HCV) during colonoscopy diagnosis. Virology Journal 2010 7:217.

\section{Submit your next manuscript to BioMed Central and take full advantage of:}

- Convenient online submission

- Thorough peer review

- No space constraints or color figure charges

- Immediate publication on acceptance

- Inclusion in PubMed, CAS, Scopus and Google Scholar

- Research which is freely available for redistribution

Submit your manuscript at www.biomedcentral.com/submit
Ciomed Central 